\title{
Application of the innovation systems framework in North-South research
}

\section{Andy Hall and Rasheed Sulaiman V.}

\author{
Keywords \\ Innovation systems, \\ crop-post harvest \\ research \\ South Asia \\ pro-poor \\ institutional learning. \\ partnership \\ evolving roles \\ North-South collabora- \\ tion \\ action research \\ DFID
}

1 The term institutional is used in both the sense of the embedded concept referring to the behaviour of individuals and physical organisations, as well as in the sense of the wider policy and political economy environment in which they function, i.e. the wider institutional context.

2 The authors acknowledge the efforts of the global CPHP team in developing and applying its research management approach. The events discussed in this paper, however, relate principally to experience in South

\begin{abstract}
This paper discusses the evolution of a development assistance research programme in South Asia. The programme supports North-South collaboration in the area of crop post-harvest issues. A novelty of the programme is the way it commissioned policy research on institutional issues impinging on the success of the research projects it commissioned. Through this and other learning activities, the programme has evolved the underlying principles of its approach. recently giving much more emphasis to the role of partnerships and institutional contexts in the planning and execution of its work. Underpinning this has been an exploration and application of the innovation systems framework. Lessons include the need to see North-South research collaboration in terms of its capacity development effects on national systems of partners and processes concerned with the development and use of innovations. Development assistance agencies should pay attention to the importance of engaging in their own institutional learning if they want to make more effective contributions to sustainable development through North-South research partnerships.
\end{abstract}

\section{Introduction}

This paper discusses changing patterns of North-South partnership and the role of policy research and institutional learning. The authors address the issue from the perspective of a policy researcher exploring partnerships in natural resources $\mathrm{R} \& \mathrm{D}$ and a research manager with responsibilities for the planning and coordination of a development assistance research programme in South Asia. The authors also bring the perspective of research professionals dealing with the practical realities of working in national and international agricultural research organisations, which face the challenge of adopting working norms and patterns of partnerships that enable them to meet contemporary development imperatives.

Stemming from these perspectives, the paper presents the co-evolving experiences of policy research and research management and implementation. The key elements concern the way a research exploration of innovation processes led to the adoption of a systems conceptualisation of change and the recognition that research needed to be viewed as an activity embedded in institutional $^{1}$ contexts. This, in turn, led to research management strategies that gave greater attention to the nature of partnerships. These developments have taken place in one of the UK Department for International Development (DFID) natural resources research programmes, the Crop Post-Harvest Programme (CPHP). The discussion relates specifically to the activities of the CPHP regional programme in South Asia. ${ }^{2}$ 
The main message from this paper does not relate to North-South partnerships alone. Rather, it is the generic issue of the way innovations emerge from and are shaped by the broad range of relationships and the wider institutional context associated with agricultural R\&D. Developing the innovative capacity of these systems of actors and institutions through stronger institutional learning and change is a major task which North-South partnerships need to focus on. Implicit in this is a much stronger capacity development agenda.

The remainder of the paper begins by providing the context of the developments described. This includes the evolution of the CPHP, and the historical development of projects that led to policy research examining the innovation systems framework. The central discussion in the paper concerns the way this systems conceptualisation informed research management philosophy and practice and some of the lessons emerging from this institutional learning. Three case studies are presented to illustrate how this has worked in practice. We conclude with a discussion of the broad policy implications of these developments for North-South research partnerships.

\section{The DFID development research assistance context}

CPHP is one of DFID's ten centrally managed natural resources research programmes. It commissions research mainly on technology development and promotion related to the post-harvest sector. CPHP focuses its work in four regions. namely. East Africa. West Africa. Southern Africa and South Asia. The discussion in this paper relates principally to developments in the South Asia regional programme since 1995 .

CPHP and the rest of the ten centrally managed programmes collectively form DFID's renewable natural resources research strategy (RNRRS), a ten-year research strategy running from 1995 to 2005. The RNRRS has evolved considerably since its inception. This in part was a consequence of how DFID's agendas have changed during this period - notably, a strengthened poverty focus and the adoption of the Millennium Development Goals as overarching performance targets. The individual programmes have also interpreted the RNRRS in different ways, and have evolved management strategies to suit alternative approaches and perspectives. So, for example, CPHP was the only programme to appoint regional coordinators located in-country. Despite these differences, the RNRRS provided (and continues to provide) a broad framework in which DFID's research for development assistance is planned and executed. This framework has informed to a large degree the nature of North-South partnerships. General features of the RNRRS include the following:

- The RNRRS was conceived and promoted as a means of exploiting the UK science base in support of international development. Programme funds were competitively managed. but since the practice was that UK institutions led the projects, competition for project funding is effectively UK-based. Project ideas were mainly developed by UK scientists. Where collaboration and consultation took place. this tended to be with a narrow set of non-UK-based scientific stakeholders. It was not uncommon for project funding to be approved without any genuine consultation with the named collaborators.

- The structure of the RNRRS programmes also reflected the fact that the strategy was designed to support UK-based institutions. The programme was divided along disciplinary lines that tended to conform to the institutional
Asia and the interpretation of this, and any errors in this are the responsibility of the authors alone. 
grouping of UK tropical agricultural expertise. Historically, this expertise had either been part of DFID itself. or had received core funding prior to the RNRRS. For example, the CPHP area was almost entirely analogous to parts of the Natural Resources Institute, a privatised former agency of DFID.

- The programmes were monitored in terms of progress in production systems - for example, yield improvement in the semi-arid production system, or post-harvest loss reduction in the high potential production system. These technical outputs would be translated into poverty/developmental impacts: and the factors governing this process were relegated to the 'assumptions' column of the logical framework. This meant that: (i) many organisations and activities that are related to and supportive of technical and economic change were assumed to be external to the research process: and (ii) since it was assumed that roles and relationships were functioning efficiently. examining the validity of these assumptions as well as the influence of the wider institutional context governing the change process was considered to be beyond the purview of research projects. Capacity building. even in the narrow sense of training, was discouraged: and the wider system changes that may have reflected the emergence of new capacities were not included in the monitoring of programme progress.

These arrangements changed over time, not least because DFID made a major shift in 1997 towards the adoption of development programmes with an explicit poverty focus. This resulted in attempts to fit research into a more peoplefocused development paradigm. However, the overall framework for research support was highly linear, premised on the assumption of transferability of knowledge. This was reflected in the relationship between Northern and Southern partners and in terms of the assumptions that new knowledge would automatically find 'target institutions' that would transfer it to 'target beneficiaries'. This classic approach to transfer of technology was embedded in the project cycle design. Participatory approaches were adopted in some research domains as a way of exploring technology-user contexts; but these rarely acknowledged the wider institutional context and the way it largely determined the direction of the project cycle.

\section{Evolution and context of the CPHP interest in innovation systems in India}

The interest of CPHP-South Asia in the institutional context of R\&D and in the innovation systems framework started in 1997. A series of projects were commissioned to provide technical backstopping to parts of the horticultural export sector. These projects were commissioned in the context of the efforts made by the Indian export development authority (APEDA) to improve fruit quality and develop sea shipment protocols for mangoes. APEDA did this by contracting Indian horticultural and post-harvest scientists to develop technical protocols for farmers' associations and export companies. In line with the conventions of the time, CPHP's assistance came in the form of a tightly focused technical project developed and implemented by UK scientists. The organisational focus of the projects was a farmers' association in the State of Andhra Pradesh, where UK and Indian scientists worked together to develop technical protocols. As this work progressed, it became apparent that constraints to the development of the horticultural export 
sector would not be solved by a simple technical backstopping approach. After all. India has extensive scientific infrastructure and human resources.

In fact, the true nature of the problem encountered was one of mobilising the different parts of the public-sector research system to act in consort to be able to deal with quality management issues in an integrated production and post-harvest chain. The attempt of UK scientists to devise a sea shipment technical protocol was not in itself going to address this broader problem. Without a greater degree of articulation between different scientific actors and also between scientific actors and export actors. the technical and managerial innovations necessary to create a mango export supply chain were simply not going to emerge. At the same time, there was apparently no other mechanism or agency that could help link up the different parts of the public-sector research system with farmers associations and private companies. Furthermore, as private organisations moved into the horticultural export sector. they were entering into alliances with other. often private, actors as a way of accessing technology. While these developments demonstrated the potential importance of emerging organisational groupings, it was difficult to see how the public-sector research system related to these developments.

It was at this point that both the farmers' association collaborating in the project, and the UK scientists realised that the true nature of the task was as much institutional as it was technological. The CPHP regional coordinators and policy researchers (i.e. authors of this paper), recognised that if these institutional developments were to be resolved, understood and exploited. much greater attention would need to be given to understanding the overall institutional context. its nature and the way it was evolving. ${ }^{3}$ It was this realisation in late 1997 that led to the research partnership between the two authors and ultimately to a policy research project exploring and applying the innovation systems concept.

There were a number of phases between this realisation of the need to explore the research process in more detail and the final adoption by the CPHP of the innovation systems framework as its overall guiding principle. These phases, summarised in Table 1, provide the basis for our discussion later in this paper. It is apparent from the table that the iteration between research on innovation processes and the changes in the research management strategy of the CPHP built up over a number of years. The process involved institutional learning by the programme, achieved through many processes. However, two critical factors stand out. Firstly, innovation research was embedded within the management team of the programme: and secondly, the commissioning of a formative review on partnerships and associated issues (Biggs and Underwood 2001) acted as a way of crystallising thinking and experience from across the global CPHP programme.

\section{The Southern context of policy research on innovation systems}

While the Northern development assistance partner had encountered the need to give closer attention to institutional issues affecting research projects, the Southern policy research partner had recognised that these same issues were impinging on wider agricultural R\&D efforts in India. Underpinning these challenges is the historical pattern of institutional development in agricultural research in India. According to these conventions, research expertise was located in disciplinarily specialised (and isolated) organisations; research and
3 These issues are discussed in detail in Hall et al. (1998. 2001. and 2002). 
Evolving Phases of Research and Research Management Practices in CPHP

\begin{tabular}{|c|c|c|}
\hline Period & Evolution of innovation research & Evolution of research management \\
\hline $1995-97$ & $\begin{array}{l}\text { Early technology projects exploring } \\
\text { narrow scientific questions. Projects led } \\
\text { exclusively by Northem partners. }\end{array}$ & $\begin{array}{l}\text { Establishment of the programme with a } \\
\text { goal of exploiting UK science for } \\
\text { development. Projects led from UK. } \\
\text { Research management principles } \\
\text { broadly adhering to linear transfer of } \\
\text { technology. }\end{array}$ \\
\hline 1997 & $\begin{array}{l}\text { Institutional issues started emerging as } \\
\text { important in South Asia. Projects were } \\
\text { achieving technical goals, but this was not } \\
\text { necessarily leading to technical and socio- } \\
\text { economic change. }\end{array}$ & $\begin{array}{l}\text { First steps towards decentralisation with } \\
\text { the creation of in-country regional } \\
\text { coordination to strengthen local } \\
\text { partnerships. }\end{array}$ \\
\hline 1998 & $\begin{array}{l}\text { Pilot project in South Asia exploring the } \\
\text { codependence of institutional and } \\
\text { technological analysis and learning. }\end{array}$ & $\begin{array}{l}\text { CPHP starts to use programme } \\
\text { development funds to explore } \\
\text { institutional issues associated with } \\
\text { R\&D and the implications for future } \\
\text { research. } \\
\text { CPHP commissions output to purpose } \\
\text { review. This concludes that projects are } \\
\text { scientifically successful, but the impact } \\
\text { on the programmes developmental } \\
\text { purpose is unclear. } \\
\text { M\&E advisor appointed. }\end{array}$ \\
\hline $1999-2002$ & $\begin{array}{l}\text { Experimental portfolio of projects } \\
\text { exploring innovation processes. Involved } \\
\text { the development and use of the innovation } \\
\text { systems framework to explore partnerships } \\
\text { and processes in cluster of CPHP technical } \\
\text { projects in South Asia. }\end{array}$ & $\begin{array}{l}\text { CPHP commissions its first major } \\
\text { project examining partnership and } \\
\text { institutional issues affecting the post- } \\
\text { harvest sector. This forms guiding } \\
\text { principle for South Asia region. } \\
\text { Partnerships advisor appointed. } \\
\text { Subsequently, CPHP commissions } \\
\text { formative review on partnerships in the } \\
\text { research process. }\end{array}$ \\
\hline $2002-03$ & $\begin{array}{l}\text { Portfolio of projects with a research and } \\
\text { capacity development agenda, seeking to } \\
\text { strengthen local innovation systems } \\
\text { through technical and institutional learning } \\
\text { and change. Projects mainly led by } \\
\text { Southem partners. }\end{array}$ & $\begin{array}{l}\text { Programme adopts innovation system as } \\
\text { guiding principle, seeking to establish } \\
\text { coalition projects principally based on } \\
\text { local partnerships. Changes } \\
\text { accompanied by significant degree of } \\
\text { programme decentralisation. }\end{array}$ \\
\hline
\end{tabular}

Table 1.

extension tasks were viewed as organisationally and institutionally separate: the evaluation tradition was not linked to the evolving development goals of the country: and the relationship with the private and NGO sectors was viewed with a great deal of apprehension.

As a result of this pattern of development, the on-going reform process of the Indian public-sector agricultural research arrangements has been circumscribed by conventions in the science/society relationship that may no longer be appropriate to the demands of the contemporary development agenda (Rajeswari 1999: Hall et al. 2000). Against this setting, a number of critical questions emerge: (i) the need to find ways in which the country's strong scientific resources can be realigned with national priorities; (ii) how these priorities can be developed in a more consensual fashion, taking into account the divergent needs of stakeholders, particularly the poor; and (iii) the way the complementary resources, skills, perspectives and agendas of these stakeholders can be effectively networked (Sulaiman and Hall 2002). It is these generic questions that CPHP shares in its efforts to devise a more effective research management strategy. 


\section{The innovation systems perspective}

The policy research project consequently turned to Lundval's (1992) idea of a 'national system of innovation', subsequently referred to as the innovation systems framework. At its simplest, this idea contains two elements. Firstly, it asserts that innovation (technical and economic change) takes place through the iterative interaction of both research and non-research actors. Secondly. it acknowledges that these actors are always embedded in a wider political, social. economic and cultural environment, and that this impinges on the way interactions between actors lead to different innovation outcomes. Thus, the collective effect of interactions of these actors in this wider institutional context represents a capability to innovate. This capability depends on the pattern of relationships linking the different actors, and the relative ability of the system to evolve new patterns of interaction. as needed, through institutional learning. The innovation systems framework helps to analyse these relationships and the resource and knowledge flows that they imply. The emphasis on the relationship between actor agendas and innovation outcomes assumes great importance where policy objectives include, for example. promoting poverty reduction or environmental sustainability. coping with HIV/AIDS and so forth.

Having recognised that the innovation systems framework could provide a useful way of understanding the institutional environment of the R\&D and technology policy activities of CPHP in India, further work was needed to apply the idea to the study of developing country agriculture. The idea of the innovation systems framework had previously been used in the context of mainly the industrial sector in developed countries. ${ }^{4}$

\section{Learning through an experimental portfolio of projects}

There were two notable features to the CPHP policy research project on innovation systems in India. Firstly, the Northern partner in the project had a research coordination role for CPHP in South Asia. In effect, this meant that the project played an institutional learning role, informing strategy development of CPHP in the region. The second feature was the way this policy research project was contingent on the wider CPHP portfolio of projects in India for empirical insights into new patterns of partnership, research processes and related institutional innovations.

The way this was approached in practice involved creating a two-tier structure of projects. This contained an 'umbrella' policy project dedicated to the conceptual and methodological development of the innovation systems framework. At the same time, a cluster of 'technical' projects was developed which. by virtue of the patterns of partnerships it involved, would make useful case studies that would allow the policy project to test and develop its innovation systems framework ideas. This process started in October 1999 with the commissioning of five projects.

\section{Case studies from the experimental portfolio Case study 1: Strengthening the nodal function of farmers' associations in post-harvest innovation systems}

This project built on earlier CPHP work on horticultural export technical backstopping. It contained an explicit attempt to help strengthen the ability of farmers' associations to access and coordinate appropriate technical assistance from public scientific organisations in India. At the centre of this was a moni-
4 Similar ideas had previously been suggested by others in the context of the agricultural sector. notably Biggs' 1990 discussion of multiple sources of innovation. 
5 For further details of the evolution of this project. see Hall $e t$ al. (2002).

toring system design to monitor both the technical and institutional aspects of a training and technical assistance programme implemented by the Indian Export Development Authority.

The objective was to introduce two elements into the horticultural innovation system: firstly, an explicit attempt to introduce more systems-oriented technical backstopping approaches, i.e. more coordinated and productive linkages between different scientific actors and between them and other stakeholders in the system: and secondly, to challenge institutional assumptions about service delivery and, in this way, to stimulate evolutionary institutional change. The second element of this project was particularly ambitious as it assumed that a monitoring system of this type would be welcomed by all stakeholders as a consensual management tool. In actual fact, and in retrospect not surprisingly, it was viewed as deeply threatening to established patterns of professional behaviour and authority.

The project was unfortunately not able to achieve what it set out to do. There are many case-specific reasons for this. Perhaps of interest here is the difficulty of a Northern project leader maintaining momentum in-country. Another problem was the difficulty of maintaining (achieving) the commitment of stakeholders to confront the uncomfortable realities of critical assumptions about institutional roles of key actors. In all fairness to the Southern partners, the agenda of institutional change was downplayed by the Northern partners in the misguided hope that it would become all too apparent to all concerned. As a result, it was difficult from the outset to build a consensus around the concept that technological change was inextricably linked to institutional learning. To make the same point in another way. a project such as this could probably only succeed if the institutional learning and change agenda emerged from and was shaped by the local actors and contexts involved. Creating the condition for this to happen is a very large question in itself. However, a lead role for local organisations in this process would be one of the implications of this line of thinking. ${ }^{5}$

\section{Case study 2: NGO-led approaches to facilitating the creation of new post-harvest innovation system capacity}

This project was led by a large UK-based NGO in collaboration with an Indian NGO. Over the last ten years, the Indian NGO has developed an approach to technology delivery to the poor. This involves using commercial marketing principles to identify technology demands, identifying or adapting suitable technology and establishing networks to produce and sell it to rural households. This has been done with great success in the context of small-scale irrigation/water resources technology. What is interesting about the approach is that it fills a niche between the conventional public-sector development interventions and the activities of the mainstream commercial sector. In doing so, it establishes a set of technology-producer/retailer-technology-user linkages that would arguably not have emerged without external assistance, but which will subsequently underpin private-sector involvement.

The CPHP project concerned applying this approach to post-harvest technology in the context of small-scale producers of vegetables for the Indian domestic market. The project was speculative in the sense that the approach appeared interesting. but it was not clear how it would be operationalised for a broad 
technological sector such as post-harvest. Initially, the CPHP advisory committee was reluctant to support a project that involved: (i) testing and developing an institutional innovation for application in the post-harvest arena: (ii) a processdriven approach where key outputs would be process lessons: and (iii) no technical constraint focus and no initial indication of what the technical output might be. These concerns were eventually overcome by reassurances that the project in all likelihood would deal with packaging or storage issues.

What was interesting in terms of the North-South partnerships was that while the Indian NGO had the practical experience and skill of establishing networks, the UK NGO (in theory, at least) had research skills and expertise in specific technical and social science areas related to post-harvest technology. At the outset, the Indian NGO had recognised that it had no specific expertise related to post-harvest. It, therefore, made the decision that the project would be implemented by building a series of relationships with a range of actors associated with the development and supply of technology and services to rural communities. The Indian NGO's other role, in addition to building these relationships, was to identify the particular technology niche using the procedures it had earlier developed in the context of water resources technology.

When reviewed by CPHP South Asia, it was found that the Indian NGO had created a broad-based grouping of partners around the development and supply of improved tomato packaging technology - the identified niche technology. In effect, it had established the linkages to construct an operational theme based on the local innovation system. This included partnerships with scientists from a national research institute who undertook extensive and fairly sophisticated adaptive trials: with local grassroots NGOs who had already established a relationship with farmers and rural communities; and with the local agricultural university for information on local crop production systems. It included publicand private-sector cardboard box manufactures: and also traders and market actors involved in distributing and popularising cardboard boxes as a replacement for wooden crates. Later on. a microfinance organisation was added to this cluster. The NGO sat at the centre of this web of actors and made explicit efforts to manage the relationships involved. Its key role was to ensure that these relationships led to the overall objective of introducing a post-harvest innovation appropriate to small-scale producers.

In these relationships, the Northern partner was not able to play the role that had initially been anticipated and the relationship between the two partners had not altogether been an easy one. There are many case-specific reasons for this. However, the generic issue was that where an R\&D initiative is going to rely on the establishment of a coalition of different actors in-country, it makes sense to have the in-country partner take the lead in this type of initiative. A related issue in this project was the history of the relationship between the two NGOs. The UK NGO had effectively contracted the Indian NGO to undertake research in previously 'collaborative' projects. The post-harvest project was not presented to CPHP as this type of arrangement. but as the project was implemented it became clear that the relationship between the two NGOs was one of 'donorship' rather than partnership. ${ }^{6}$

In the case of this project, the leadership was shifted by CPHP to the Indian NGO. This caused protests from the UK NGO. With the Indian NGO leading the project, it could now draw down assistance from its Northern partner as
6 For example. the UK NGO would not disclose the budget to the Indian NGO. Another example related to ownership of the project results. The UK NGO requested the Indian NGO to enter into an agreement whereby the results would be only be promoted by the IK NGO. 
7 For further details of the lessons from this project, see Clark et al. (2002).

8 The authors are grateful to Dr Stephen Biggs for pointing this out to them during a programme review. required. In fact, it usually does this is in the context of reporting progress to the CPHP in an 'acceptable' format, rather than specific technical support. To date. this project has been enormously successful in introducing a major packaging innovation. This has reduced the vulnerability of small-scale tomato producers to environmental policy changes that would prompt the technological obsolescence of existing timber-based packaging materials.?

\section{Case study 3: Policy paper, policy networks and the wider insti- tutional context of partnerships}

The third case study concerns the North-South partnership between the authors of this paper and the policy research project on innovation systems they collaborated on. As discussed elsewhere, the project held interest for both partners. Since 1999. both partners have undertaken a series of case studies, have coauthored papers and presented these at national and international meetings and conferences (see. for example. Hall et al. 2001: Hall et al. 2002; Sulaiman and Hall 2002). The partnership worked well and continues to be intellectually simulating. A significant number of policy documents have been produced. But what was the policy impact of this research and its value to North-South partnership? Learning from this project has significantly influenced the research management approach of the CPHP in South Asia. However, in terms of the agricultural research paradigm in India. initially at least, the impact is probably quite limited. There are two reasons for this, both related to what the research has revealed about the institutional context of India and the implications of using an innovation systems approach.

Firstly, the Indian public-sector agricultural research system is strongly wedded to the linear paradigm of R\&D planning, execution and evaluation. This paradigm permeates the whole organisational culture of ICAR and informs the majority of the 'agricultural technology for development' discourse in the country. Secondly, exploration of the innovation systems framework has highlighted the need to introduce institutional experimentation and learning: the need to strengthen genuine partners with private and non-research actors; the need to build coalitions or task networks around common themes and areas of interest: and the need to explore the institutional context that impinges on these processes.

These findings provide useful insights for policy and practice. However, the Northern and Southern partners failed to heed the advice they were promoting as policy researchers - i.e. the need to develop their own coalition around the promotion of the innovation systems framework as an alternative approach to R\&D in India. ${ }^{8}$ Without the creation of such a network of support and advocacy. a policy research project stands little chance of creating a new consensus that can challenge the normative organisational culture of a large public agency such as ICAR. The project went on to address this need by networking with likeminded policy researchers and practitioners. To this end, it employed networkbuilding devices, such as: special issue journal publication. commissioning reviews of CPHP to be done by Southern rather than Northern consultants: working with Southern private consulting and advisory services; and using commissioned studies as a way of building ownership and consensus in the research community. Success in building these coalitions will always, to some extent. remain an empirical question. 
A further point about this policy research on innovation systems concerns the extent to which it addresses the need to devise institutional arrangements that support pro-poor innovation. The challenge in South Asia of introducing institutional learning and change to create more effective innovation systems in a general sense is so great that it is easy to lose sight of the need for strengthening the capacity of these systems to generate pro-poor innovations. ${ }^{9}$ Again, this has implications for the type of coalition that needs to be established around this area of policy research as well as the way progress towards this policy goal is evaluated.

\section{Programme response to partnerships: adoption of the coalitions approach}

While the issues outlined in these case studies were emerging from work in South Asia, the CPHP had also recognised that partnerships of various types were becoming important at global level. Driving this was the emerging importance of partners who were not from public-sector research organisations. Such partnerships emerged as projects began to focus on the 'uptake' pathways for their findings and the need to somehow embed these in research design was felt. As an initial response, the CPHP programme appointed a consultant to advise on partnership issues. In August 2001. CPHP went one step further by commissioning a formative review to help it develop a programme strategy with respect to partnerships. The review highlighted the central importance of understanding the nature of partnerships and the institutional context that shapes them. As a way of managing this more effectively, it recommended that the innovation systems framework be used as the guiding principle across the whole of the CPHP research programme (Biggs and Underwood 2001). The global CPHP adopted this recommendation and used it to underpin the technical proposal that it presented to DFID explaining how it planned to implement the CPHP in its final phase, 2002-05. CPHP refers to this as the 'coalitions approach'.

This new approach has a number of implications. including the adoption of an action research methodology: a shift to mainly Southern partner-led projects: a greater emphasis on facilitated project development and on projects exploring both technical and institutional aspects of research themes; a greater emphasis on institutional learning: and an explicit capacity-building development.

In practical terms, this meant that instead of releasing a call for research proposals. (to which the UK research community would respond, as in the past), the programme's regional coordinators became responsible for developing coalitions of actors around a limited number of technical or policy research themes. These nascent partnerships would then form the basis for the negotiation of action research projects. This does not exclude Northern partners. Rather, it recognises that coalitions need to be established in-country around a particular theme identified and defined by in-country partners based on their technical and institutional understanding of the research task. The membership of each coalition and the role (or roles) of the actors will then be determined by the nature of the theme and the local institutional context in which the coalition is being developed. This implies a greater degree of accountability (to the coalition) for research partners.

To date, the early phases of project development using these principles have been completed. Four lessons emerge from this experience. Firstly, the concepts underpinning this new approach were much more difficult to communicate to 
research partners and colleagues than was imagined at the outset. This led to different interpretations of what this approach meant and how it should be implemented. Such diversity introduces both strengths and weaknesses.

A second related point is that while project partners (in South Asia) quickly accommodated the idea of working as part of a broad-based coalition, the notion of documenting process activity and institutional lessons arising out of this experience seemed counter-intuitive to many. It was seen in some way as 'nonscience'. Perhaps this is understandable given the reductionist research environments many partners operate in. It nevertheless reiterates the general need to encourage the development of holistic systems perspectives in research where the distinction between 'technical' and 'socio-economic' investigation is blurred.

The third lesson concerns the response from some Northern partners, some of whom appeared to feel threatened by the new approach. Issues raised by way of complaint included: lack of transparency of the project commissioning process. specifically that they had been excluded; questions over the proper use of UK taxpayers' money and the assumed rights to research funded from this source: concern about the status quo of existing partnerships being disrupted: and intellectual property rights conflicts associated with project proposals already under consideration when the coalitions approach was introduced. These concerns relate to specific instances and partners, and do not represent a general reaction to the global programme in all regions. However, it is significant that these concerns were similar to those that in the past Southern partners had experience of in North-South collaborative arrangements. The authors, perhaps naively, underestimated how strong the reaction of Northern partners would be and the level of effort required to both effectively communicate the meaning of the new approach, and dispel some of the fears and misconceptions that emerged.

The fourth and perhaps more fundamental lesson from this is that research arrangements can only change and evolve through iterations between planning and practice. No amount of paper-based planning could have anticipated the challenges encountered - or the ways of resolving them. Such details can only be developed through learning and adaptation during the process of application, responding to specific contexts.

\section{Adoption of the innovation systems framework: implications for North-South research partnerships}

The experience of policy research on innovation processes and the attempts to apply this through the experimental portfolio discussed in the case studies, and. more recently, across the global programme, suggest some fairly fundamental implications for North-South research partnerships. Four issues stand out. Firstly, success of research projects seems closely related to the characteristics of the partnership grouping or coalition around a particular problem area. This coalition needs to be predominantly made up of Southern partners. Assumptions about the institutional roles of the actors in the coalition have to be made explicit from the start and reassessed as the project proceeds. Similarly, roles will evolve as projects evolve.

This raises the second issue, namely, which is the most appropriate partnership grouping? This is an empirical question that cannot realistically be answered at the outset of a project. The implication of this is that projects 
would benefit from an action research orientation. For example, although project procedures usually offer the opportunity to adapt logical frameworks. in actual fact partners and technology trajectories are rarely changed during the project cycle. Similarly, research project procedures tend not to provide an opportunity for these to be contested in the project-level monitoring and evaluation. The related implication of an action research orientation is that the process lessons associated with technological success in projects are valid project outputs or probably innovations complementary to the new technical knowledge that projects produce. The NGO case study discussed in the previous section is a very clear example of this.

Thirdly. where a poverty focus is paramount, stakeholder analysis is needed to ensure that this agenda is promoted within the coalition. The relationship of the coalition with the wider institutional context, the effects this has on patterns of relationship and the way agendas and priorities are identified and promoted needs to be made explicit from the start of the project. The fourth point relates to the way projects are monitored. Monitoring projects for direct poverty impact makes little sense from a project-management perspective. This is because of the limited time-frame problem; the attribution problem; and, most importantly, the complex systems phenomena (i.e. livelihoods are complex systems in which future outcomes of current initiatives are unknown and unknowable). However, a useful alternative is to track poverty relevance through the project cycle. The conceptual message from the innovation systems framework is that rather than worrying about monitoring the inputs and outputs of research. it would be more useful to monitor process change. particularly the way relationships between actors are changing and leading to improved innovation performance. The latter can then be judged against a range of criteria. including poverty relevance. Again, stakeholder analysis is likely to be important in ensuring that innovation is skewed in favour of the poor. Knowledge about patterns of power and dynamics in coalitions and how this is changing in favour of desired outcomes is a key indicator of new innovation capacities. This suggests that much greater emphasis would need to be placed on assessment of the capacity development effect of projects - i.e. capacity development not in the conventional sense of building up stocks of research infrastructure and trained scientists, but rather in the sense of the collective capacity of networks or systems of actors interactively linked with the view to innovate.

It is perhaps this last point that forms the critical message for Northern development assistance agencies seeking to exploit North-South research collaboration in the cause of sustainable development and poverty reduction. Much more attention than hitherto would need to be given to the issue of capacity development in the systems sense, so that changes in the behaviour of the system and the institutions that govern it would become the primary objective of North-South partnerships. As Mosse (2001) points out, this shift in orientation is consistent with the emerging trend in development assistance where managed networks and inter-agency links and partnerships are increasingly important in meeting wider goals of policy change and institutional reform. For many development assistance agencies involved in technology development programmes, the shift in orientation will require them to embrace an agenda for institutional learning and change. National govern- 
ments may also need to adopt the same perspective in their efforts to reform public agricultural research organisations.

\section{Conclusion}

In this paper the development and use of the innovation systems framework has been used in relation to North-South research partnerships. It emerges from our discussion that the nature of partnerships will need to be made explicit in agricultural R\&D and technology policy, as it is the nature of the institutional context that largely determines the outcomes of such efforts. Establishing innovation systems that are capable of effectively responding to the needs of the poor will require attention to be focused on relationships, actor agendas and the institutional arrangements governing consensus building and stakeholder participation. This has implications not only for North-South partnerships, but also for the wider issue of formulating appropriate policies to promote science and technology-led development. Initiatives need to be firmly embedded in national stakeholder networks, and technical imperatives need to be supplemented by efforts to build new forms of multi-institutional capacity. North-South partnership should be supportive of this broadly conceived notion of capacity building. A further conclusion for development assistance agencies is that policy research on institutional arrangements that impinge on the efforts of these agencies should be firmly embedded in their own learning procedures. Only in this way will agencies be able to effectively engage with the need to continuously revisit their approaches and change accordingly.

\section{Acknowledgements}

This paper is an output from a research project funded by the United Kingdom Department for International Development (DFID). The views expressed are not necessarily those of DFID /R 7502: Crop Post-Harvest Programme]. An earlier version of the paper was presented at the International Conference on North-South Research Collaboration ( 3 December 2001), organised by the Royal Netherlands Academy of Arts and Science in cooperation with the Netherlands Ministry of Foreign Affairs, the Netherlands Foundation for the Advancement of Tropical Research and the Netherlands Development Assistance Research Council. The authors gratefully acknowledge the support granted by the organisers.

\section{References}

Biggs. S.D. (1990). A multiple source of innovation model of agricultural research and technology promotion:, World Development, vol, 18, no. 11, pp. 1481-99.

Biggs, S.D. and Underwood, M.P. (2001), Review of Crop Post-Harvest Programme, unpublished report to NR International.

Clark, N. G.. Hall. A.J., Rasheed Sulaiman V. and Guru Naik (2001). 'Research as capacity building: the case of an NGO developed post-harvest innovation system for the Himalayan Hills', unpublished manuscript.

Hall A.J.. Sivamohan. M.V.K., Clark, N.. Taylor, S. and Bockett., G. (1998), Institutional Developments in Indian Agricultural R\&D Systems: The Emerging Patterns of Public and Private Sector Activity', Science, Technology and Development, vol. 16, no. 3. pp. 51-76.

Hall. A.J, Clark, N.G.. Rasheed Sulaiman V.. Sivamohan. M.V.K. and Yoganand, B. (2000). 'New agendas for agricultural research in developing countries: policy analysis and institutional implications'. Knowledge. Policy and Techology. vol. 13, no. 1. pp. $70-91$. 
Hall A.J.. Sivamohan, M.V.K.. Clark, N.. Taylor, S. and Bockett, G. (2001). 'Why Research Partnerships Really Matter: Innovation Theory, Institutional Arrangements and Implications for the Developing New Technology for the Poor', World Development, vol. 29, no. 5, pp. 783-97.

Hall. A.J.. Clark. N.G., Rasheed Sulaiman V. and Taylor. S. (2002), 'Institutional Learning through Technical Projects: Horticultural Technology R\&D Systems in India', International Journal of Techmology Management and Sustainable Development, vol. 1. no. 1, pp. 21-39. (Also published as ODI Agricultural Research and Extension Network (AgREN) Paper, no. 111. January 2001).

Lundvall, B.A. (ed.) (1992). National Systems of Imovation and Interactive Learning. London: Pinter.

Mosse, D, (2001). 'Process-oriented approaches to development practice and social research", in Mosse. D.. Farrington. F. and Rew, A. (eds.), Development as Process: Concepts and Methods for Working with Conplexity. New Delhi. India: India Research Press.

Rajeswari. S. (1999). 'Patronage and evaluation in the Indian Council of Agricultural Research', Evaluation. vol. 5. no. 3. pp. 278-302.

Rasheed Sulaiman V. and Hall, A.J. (2002), 'Beyond dissemination: Can Indian Agricultural Extension Reinvent Itself?'. NCAP Policy Brief. no. 16. New Delhi, India: National Centre for Agricultural Economics and Policy Research, 4 pp. 
Copyright $@ 2003$ EBSCO Publishing 